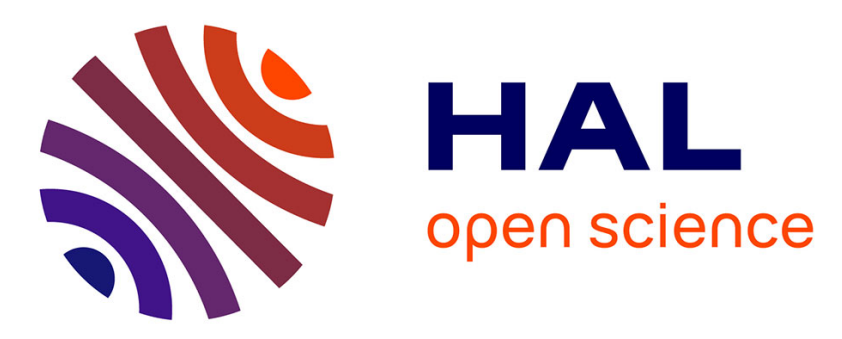

\title{
Palladium Nanoparticles in Glycerol/Ionic Liquid/Carbon Dioxide Medium as Hydrogenation Catalysts
}

Garima Garg, Anna M Masdeu-Bultó, Norberto Farfán, Javier

Ordóñez-Hernández, Montserrat Gómez, Yaocihuatl Medina-Gonzalez

\section{To cite this version:}

Garima Garg, Anna M Masdeu-Bultó, Norberto Farfán, Javier Ordóñez-Hernández, Montserrat Gómez, et al.. Palladium Nanoparticles in Glycerol/Ionic Liquid/Carbon Dioxide Medium as Hydrogenation Catalysts. ACS Applied Nano Materials, 2020, 3 (12), pp.12240-12249. 10.1021/acsanm.0c02706 . hal-03108190

\section{HAL Id: hal-03108190 https://hal.science/hal-03108190}

Submitted on 13 Jan 2021

HAL is a multi-disciplinary open access archive for the deposit and dissemination of scientific research documents, whether they are published or not. The documents may come from teaching and research institutions in France or abroad, or from public or private research centers.
L'archive ouverte pluridisciplinaire HAL, est destinée au dépôt et à la diffusion de documents scientifiques de niveau recherche, publiés ou non, émanant des établissements d'enseignement et de recherche français ou étrangers, des laboratoires publics ou privés. 


\section{Palladium Nanoparticles in Glycerol/Ionic}

\section{Liquid/Carbon Dioxide Medium as Hydrogenation}

\section{Catalysts.}

Garima Garg, ${ }^{1,2}$ Anna M. Masdeu-Bultó, ${ }^{3}$ Norberto Farfán, ${ }^{4}$ Javier Ordóñez-Hernández, ${ }^{4}$ Montserrat Gómez, ${ }^{2, *}$ and Yaocihuatl Medina-González $z^{1, \dagger, *}$

${ }^{1}$ Laboratoire de Génie Chimique, Université de Toulouse, CNRS, INPT, UPS, 4 Allée Emile Monso, CS 84234, 31030 Toulouse, France.

${ }^{2}$ Laboratoire Hétérochimie Fondamentale et Appliquée, UMR CNRS 5069, Université Toulouse 3 - Paul Sabatier, 118 route de Narbonne, 31062 Toulouse cedex 9, France.

${ }^{3}$ Department of Physical and Inorganic Chemistry, Universitat Rovira i Virgili, 43007 Tarragona, Spain

${ }^{4}$ Facultad de Química, Departamento de Química Orgánica, Universidad Nacional Autónoma de México, 04510, Ciudad de México, México

${ }^{\dagger}$ Permanent address: Centre National de Recherche Scientifique, Université de Bordeaux, Solvay, LOF, UMR 5258 CNRS Solvay, 33600 Pessac, France. 
* Authors to whom correspondence should be addressed: gomez@chimie.ups-tlse.fr, yaocihuatl.medina-gonzalez@u-bordeaux.fr

\section{KEYWORDS}

$\mathrm{CO}_{2}$, DES, micro-viscosity, diffusion, fluorescent molecular rotors, palladium nanoparticles, hydrogenation, $\mathrm{scCO}_{2}$ extraction.

ABSTRACT: In this work, the influence of carbon dioxide on the synthesis of palladium nanoparticles (PdNPs) in glycerol/ionic liquid mixtures and their further applications in catalytic hydrogenations, was studied. In the glycerol/choline tosylalaninate $/ \mathrm{CO}_{2}$ medium, small and very well-dispersed metal nanoparticles were obtained $(1.3 \pm 0.3 \mathrm{~nm})$, exhibiting a relative narrow size distribution. Palladium nanoparticles prepared in the presence of supercritical carbon dioxide $\left(\mathrm{scCO}_{2}\right)$ showed higher catalytic reactivity in comparison with those prepared in its absence. In addition, we observed a beneficial effect of $\mathrm{CO}_{2}$ in the studied hydrogenations. With the aim of rationalizing this trend, measurements of viscosity of the solvent media were carried out by using fluorescent molecular rotors, allowing the determination of diffusion coefficients for the organic substrates and molecular hydrogen. This study evidenced that $\mathrm{CO}_{2}$ causes a decrease of the viscosity of the medium and an increase of the diffusion constants of reagents including $\mathrm{H}_{2}$; consequently, PdNPs in the glycerol/choline tosylalaninate/ $\mathrm{CO}_{2}$ solvent showed an enhanced catalytic activity. From both process engineering and environmental points of view, it is important to highlight the efficiency of the extraction of organic products from the catalytic glycerol/ionic liquid solution by $\mathrm{scCO}_{2}$. 


\section{Introduction}

The beneficial effect of $\mathrm{CO}_{2}$ in sub- or super-critical conditions in catalytic processes, in particular for hydrogenation reactions, is well-known in the literature, mainly involving supported metal-based catalysts. ${ }^{1-3}$ The full miscibility of $\mathrm{CO}_{2}$ with $\mathrm{H}_{2}$ together with the high diffusivity and good transport properties of this fluid represent the foremost physico-chemical reasons for achieving high reaction rates in comparison with hydrogenations carried out in conventional organic solvents.

$\mathrm{ScCO}_{2}$ has been also applied in the synthesis of metal-based nanomaterials. In contrast to the supercritical fluid chemical deposition methodology to prepare metal nanoparticles (MNPs) supported on solid supports, ${ }^{4-7,8,9}$ the synthesis of support-free MNPs in $\mathrm{scCO}_{2}$ has been less studied. The pioneering work reported by Korgel and co-workers concerned the synthesis of AgNPs in neat $\mathrm{scCO}_{2}$ using perfluorodecanethiol as $\mathrm{scCO}_{2}$-soluble stabilizer. ${ }^{10}$ Based on this strategy, PdNPs and AgNPs were also prepared under flow conditions. ${ }^{11}$ Later on, AgNPs were prepared by the polyol approach assisted by $\mathrm{scCO}_{2}$, using ethylene glycol as both co-solvent and reducing agent, and polyvinylpyrrolidone as stabilizer. ${ }^{12}$ In all these reports, uniform and better dispersed nanoparticles were obtained, in relation to those prepared in usual organic solvents.

However, working in neat $\mathrm{scCO}_{2}$ as solvent shows some limitations such as the low solubility of some reagents and catalysts. Combining compressed gas and liquid solvents (organic solvents, ionic liquids, deep eutectic mixtures), called gas-expanded liquids, benefits of advantages of both gas and liquid partners. ${ }^{13,14}$ Furthermore, it is known that a number of ionic liquids can be dissolved in $\mathrm{scCO}_{2}$ in the presence of polar compounds (such as acetone, ethanol, ethylene glycol); this effect is very restricted when apolar compounds are involved (e.g. alkanes). ${ }^{15,16}$ Concerning ionic liquids, 
Deep Eutectic Solvents (DES) have attracted great attention as reaction media in the last years, as an answer to the need of greener, less toxic, and non-volatile solvents. Interestingly, one of the most typical DES, i.e. choline chloride/glycerol, has been reported to be comparable in cost to some organic solvents, which comes from the large availability of choline chloride and glycerol. ${ }^{17}$ DES have been proposed as solvent media in catalytic processes, mainly due to the ability to tailor their solvent capabilities by changing the constituents of the DES that can be judiciously chosen to obtain a compound of low toxicity and with the desired physicochemical properties. ${ }^{18}$ Nevertheless, and even though the several advantages of DES, some drawbacks can interfere with their implementation in large scales such as their high viscosity and their difficult recyclability. Concerning the viscosity, highly viscous solvents $(>100 \mathrm{cP})$ can hinder mass transfer during chemical reactions, affecting kinetics and selectivity of the transformation. For instance, during hydrogenation reactions in highly viscous media, a decrease of $\mathrm{H}_{2}$ diffusion can be expected, imposing high pressures of hydrogen to obtain acceptable conversions and thus increasing risks in terms of safety. On the other hand, recyclability of DES is typically performed by biphasic extraction of products using an immiscible organic solvent or by dissolving the DES in water in order to perform the separation; both strategies need the drying of the DES, which can be highly energy and time consuming in particular if the latter strategy is used. In the case of the first strategy of separation of DES, emissions of volatile organic solvents can be an important issue. Accordingly, extraction of products and recycling of DES represent key steps to be improved in order to develop applications of DES at industrial scale.

Curiously, few applications have been reported involving unsupported metal nanoparticles (in particular palladium-based catalysts) in the presence of $\mathrm{CO}_{2}$ for applications in hydrogenations, all of them involving water as (co)solvent (see Table S1 in the Supporting Information). ${ }^{19,20,21,22}$ 
In this context, high-pressure $\mathrm{CO}_{2}$-based systems appear as an appropriate approach to attain both objectives: i) decreasing viscosity to improve diffusion during hydrogenation reactions and ii) proposing a process including an easy and feasible extraction step. Specifically, we studied the glycerol/choline-based derivative/ $\mathrm{CO}_{2}$ system as solvent for both the synthesis of unsupported palladium nanoparticles (PdNPs) and catalytic hydrogenations (Figure 1).

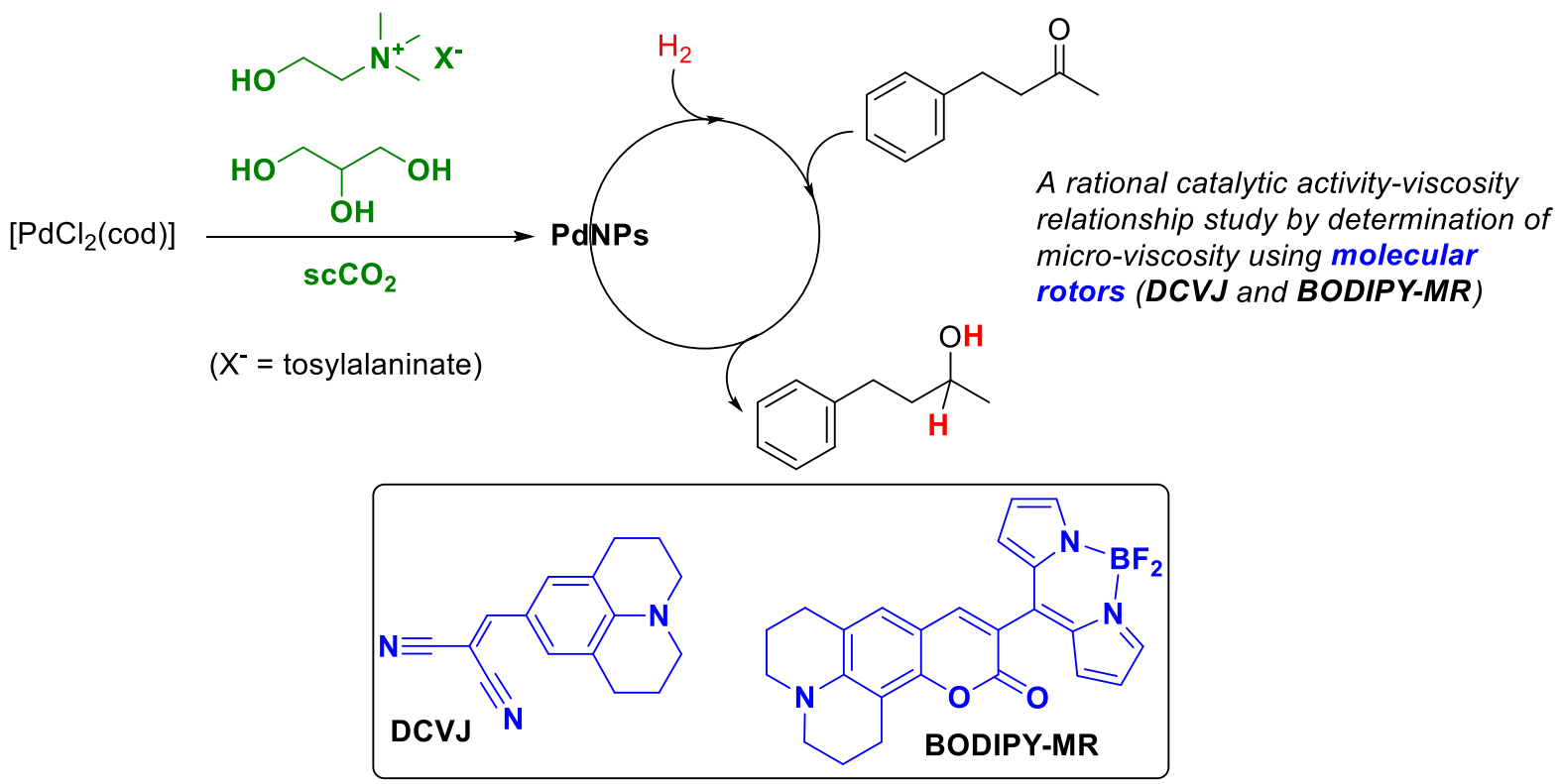

Figure 1. Scheme that represents the main objective of this work.

With the purpose of rationalizing the observed behavior, the determination of physicochemical properties of the solvent such as viscosity is crucial. Thus, we determined the viscosity under high pressure conditions. For that, measurements using two fluorescent molecular rotors were implemented (Figure 1). ${ }^{23-25}$ The use of these molecular rotors as viscosity probes, allows the study of microviscosity which can be particularly important in highly heterogeneous media, and also permits to measure the viscosity without the use of expensive high-pressure rheometers.

\section{Experimental Section}




\subsection{Materials and Methods}

Unless otherwise stated, all chemical reagents and 9-(2,2-dicyanovinyl)julolidine molecular rotor (DCVJ) were purchased from commercial suppliers and used without further purification. Solvents were dried by standard methods or distilled prior to use.

Choline tosylalaninate and palladium nanoparticles (PdNPs) were prepared following reported methodologies. ${ }^{26}$ Bulk viscosity of the solvent medium was measured using a Rheometer AR2000Ex from TA Instruments. High-pressure reactions were carried out in a Top Industrie Autoclave. GC analyses were carried out on a GC Perkin Elmer Clarus 500 with ionization flame detector, using a SGE BPX5 column composed by 5\% phenylmethylsiloxane, coupled to a Perkin Elmer Clarus MS560 mass detector. NMR spectra were recorded on a Bruker Advance 300 spectrometer at $293 \mathrm{~K}$ (300 MHz for ${ }^{1} \mathrm{H}$ NMR and $75.5 \mathrm{MHz}$ for ${ }^{13} \mathrm{C}$ NMR), using chloroform-d as solvent. For the synthesis of BODIPY-MR, ${ }^{1} \mathrm{H},{ }^{13} \mathrm{C},{ }^{11} \mathrm{~B}$ and ${ }^{19} \mathrm{~F}$ NMR spectra were recorded using Varian Unity Inova 300 and JEOL ECA 400 spectrometers. High-resolution mass spectra were acquired with an Agilent Technologies ESI TOF spectrometer. TEM images of PdNPs dispersed in glycerol were obtained from a JEOL JEM 1400 instrument running at $120 \mathrm{kV}$. PdNPs size distributions and average diameters were determined from TEM images applying Image-J software associated to a Microsoft Excel worksheet. Elemental ICP-AES analyses were carried out by using a Perkin Elmer 2400 series II analyzer and an iCAP 6300 ICP Spectrometer. A SEPAREX SF200 pilot (Separex Company, Nancy, France) was used to carry out the extraction tests. Melting points were determined using an Electrothermal Mel-Temp ${ }^{\circledR}$ apparatus. Infrared spectra were obtained using a Perkin-Elmer Spectrum 400 FT-IR/FT-FIR spectrophotometer. Absorption and fluorescence spectra under ambient conditions were obtained using a Perkin Elmer Lambda 2S UV/Vis spectrophotometer and Varian Cary Eclipse Fluorescence spectrometer, 
respectively. Fluorescence spectra were recorded at $25^{\circ} \mathrm{C}$ in a $1 \mathrm{~cm}$ quartz fluorescence cuvette placed in a thermostated holder at $25 \pm 0.1{ }^{\circ} \mathrm{C}$ with a recirculating water bath. High-resolution mass spectra were acquired with an Agilent Technologies ESI TOF spectrometer.

Fluorescence spectroscopy determinations at high pressure were performed by using a stainless-steel cell of $5 \mathrm{~mL}$ with four sapphire windows. The windows were sealed with Teflon gasket joints capable of withstanding pressures up to 350 bar. The temperature control unit for the cell consisted of heating cartridges inserted into the body, probes, and a temperature controller. A blue led light source and a fluorescent detector were placed on adjacent windows of the cell making them orthogonal to each other (see Figure S1 in the Supporting Information). A StellarInc BLUEWave spectrometer was used to record the detected fluorescence on a computer.

\subsection{Synthesis and characterization of BODIPY-MR}

10-(Di(1H-pyrrol-2-yl)methyl)-2,3,6,7-tetrahydro- $1 H, 5 H$-quinolizino(9,1-gh)coumarin (0.150 g, 0.39 mmol; see synthesis methodology -Scheme S1-, NMR and UV-vis spectra -Figures S2-S4- in the Supporting Information) and 2,3-dichloro-5,6-dicyano-1,4-benzoquinone (0.100 g, $0.47 \mathrm{mmol})$ were dissolved in $\mathrm{CH}_{2} \mathrm{Cl}_{2}(5 \mathrm{~mL})$. The reaction mixture was stirred at room temperature for $2 \mathrm{~h}$, followed by addition of triethylamine $(0.81 \mathrm{~mL}, 5.8 \mathrm{mmol})$. After 10 minutes, $\mathrm{BF}_{3} \cdot \mathrm{OEt}_{2}(0.97 \mathrm{~mL}, 7.8 \mathrm{mmol})$ was added dropwise and the reaction mixture was stirred for $2 \mathrm{~h}$ and then washed with water and extracted with $\mathrm{CH}_{2} \mathrm{Cl}_{2} / \mathrm{H}_{2} \mathrm{O}$. The organic phase was filtered over $\mathrm{Na}_{2} \mathrm{SO}_{4}$, the solvent was removed under reduced pressure and the crude product was further purified by column chromatography over silica gel with hexane/ethyl acetate (85:15) as eluent to give $33 \mathrm{mg}$ of BODIPY-MR (20\% yield) as a green solid. M.p. $90{ }^{\circ} \mathrm{C}$ (decomposition) (ATR, $v$, $\left.\mathrm{cm}^{-1}\right): 3129,2954,2932,2856,1715,1619,1590,1559,1522,1389,1308,1261,1114,1078,954$. 
UV-Vis absorption. $\left(\mathrm{CH}_{2} \mathrm{Cl}_{2}\right): \lambda=567,508,404 \mathrm{~nm}$. UV-Vis emission $\left(\mathrm{CH}_{2} \mathrm{Cl}_{2}\right): \lambda=520,453$ nm. ${ }^{1} \mathrm{H}$ NMR (300 MHz, $\mathrm{CDCl}_{3}, \delta$, ppm): 7.86 (bs, 2H, H-21), 7.71 (s, 1H, H-9), 7.09 (bs, 2H, H19), 6.92 (s, 1H, H-8), 6.49 (bs, 2H, H-20), 3.34 (q, J=5.2 Hz, 4H, H-3, H-5), 2.91 (t, J=6.4 Hz, 2H, H-1), 2.77 (t, J=6.4 Hz, 2H, H-7), 2.00-1.98 (m, 4H, H-2, H-6). ${ }^{13} \mathrm{C}$ NMR (75 MHz, CDCl ${ }_{3}$, $\delta$, ppm):160.5 (C-11), 152.6 (C-12), 147.8 (C-14), 146.5 (C-9), 143.9 (C-21), 142.0 (C-17), 135.2 (C-18), 130.4 (C-19), 126.2 (C-20), 119.4 (C-10), 118.2 (C-8), 112.2 (C-15), 107.6 (C-16), 106.3 (C-13), $50.3\left(\mathrm{~N}-\mathrm{CH}_{2}\right), 49.9\left(\mathrm{~N}-\mathrm{CH}_{2}\right), 27.6\left(\mathrm{CH}_{2}\right), 21.3\left(\mathrm{CH}_{2}\right), 20.4\left(\mathrm{CH}_{2}\right) .{ }^{11} \mathrm{~B} \mathrm{NMR}(160.4 \mathrm{MHz}$, $\left.\mathrm{CDCl}_{3}, \delta, \mathrm{ppm}\right):-0.76\left(\mathrm{t}, \mathrm{J}_{\mathrm{B}-\mathrm{F}}=28.8 \mathrm{~Hz}\right){ }^{19} \mathrm{~F} \mathrm{NMR}\left(282.4 \mathrm{MHz}, \mathrm{CDCl}_{3}, \delta, \mathrm{ppm}\right):-142.51\left(\mathrm{dq}, \mathrm{J}_{\mathrm{F}-}\right.$ $\left.\mathrm{F}=105 \mathrm{~Hz}, \mathrm{~J}_{\mathrm{B}-\mathrm{F}}=28.8 \mathrm{~Hz}\right),-147.82\left(\mathrm{dq}, \mathrm{J}_{\mathrm{F}-\mathrm{F}}=105 \mathrm{HZ}, \mathrm{J}_{\mathrm{B}-\mathrm{F}}=28.8 \mathrm{~Hz}\right)$. HRMS (ESI-TOF): calcd. for $\left[\mathrm{C}_{24} \mathrm{H}_{20} \mathrm{BF}_{2} \mathrm{~N}_{3} \mathrm{O}_{2}+\mathrm{H}^{+}\right]$432.1689, found 432.1691 (0.46 ppm).

\subsection{Calibration and measurements of viscosity using fluorescent molecular rotors.}

Four solutions of different viscosity were prepared using mixtures of glycerol:ethylene glycol in the ratio of $1: 0,8: 2,6: 4$, and $4: 6$. The viscosities of these four solutions were measured using a rheometer at $60{ }^{\circ} \mathrm{C}$ and $80{ }^{\circ} \mathrm{C}$. A known quantity of a solution of molecular rotor in acetone was added to each one of the glycerol:ethylene glycol solutions; acetone was then evaporated (concentration of DCVJ and BODIPY-MR at the end was $1.12 \times 10^{-4} \mathrm{mmolL}^{-1}$ ); fluorescence spectra of these solutions were recorded using the procedure mentioned in section 2.1 at $60{ }^{\circ} \mathrm{C}$ and $80{ }^{\circ} \mathrm{C}$.

The Förster-Hoffmann equation establishes a mathematical relationship between viscosity $\eta$ and quantum yield $\Phi$ (eq. 1): ${ }^{27}$

$$
\ln \Phi=C+x \ln \eta
$$


where $C$ is a temperature-dependent constant and $x$ is a dye-dependent constant. If the absorbed light intensity is known, the emission intensity and the quantum yield are directly and proportionally related. ${ }^{28}$ At low concentrations, the intensity of emission increases linearly with the concentration of the rotor. Response of rotors can be calibrated by using fluids of known viscosity, thus permitting to determine the viscosity of an unknown fluid.

In this context, calibration curves were generated from the fluorescence data measured for different solutions prepared by varying concentrations of ethylene glycol and glycerol at different temperatures (see Figures S5-S7 in Supporting Information); their viscosity was measured by the rheometer. Calibration curves at different temperatures were then used to calculate the viscosity using the fluorescence intensity (see Section 2.4). For DCVJ, values of parameter $x$ are reported to be close to $0.6,{ }^{28}$ which is in agreement with the values obtained in this work during the calibration experiments (see Figures S8-S10 in Supporting Information).

\subsection{Determination of viscosity of choline tosylalaninate/glycerol mixtures under $\mathrm{CO}_{2}$}

The high-pressure cell (see Figure S1 in the Supporting Information) was completely filled with the above prepared DES and the corresponding molecular rotor solution (for both molecular rotors, DCVJ and BODIPY-MR, concentration was $\left.1.12 \times 10^{-4} \mathrm{mmolL}^{-1}\right)$, then the cell was tightly closed. A magnetic stirrer was used to agitate the contents in the cell to facilitate reaching equilibrium. This experiment was done at 60 and $80^{\circ} \mathrm{C}$. For each measurement, the cell was filled with a certain pressure of $\mathrm{CO}_{2}$ and kept pressurized until an equilibrium between DES and $\mathrm{CO}_{2}$ was achieved. Fluorescence spectra were recorded by the spectrometer described in Section 2.1.

\subsection{General procedure for hydrogenation using choline tosylalaninate stabilized palladium nanoparticles under $\mathrm{CO}_{2}$}


In an autoclave (working from 5 to 350 bar total pressure), the appropriate substrate ( $1 \mathrm{mmol}$ for $1 \mathrm{~mol} \%$ of catalyst or $10 \mathrm{mmol}$ for $0.1 \mathrm{~mol} \%$ of catalyst) was added to $1 \mathrm{~mL}$ of preformed nanoparticles stabilized by choline tosylalaninate ( $1 \mathrm{~mol} \% ; 2.85 \mathrm{mg}$ of $\mathrm{Pd})$ in glycerol under argon. ${ }^{26}$ The reaction mixture was put under vacuum and then pressurized with $\mathrm{H}_{2}$ and/or $\mathrm{CO}_{2}$ at the convenient pressure, heated up at $80{ }^{\circ} \mathrm{C}$ and stirred for the suitable time; then, cooled down to room temperature before extraction. Organic products were extracted from glycerol by a biphasic methodology, adding dichloromethane $(5 \times 3 \mathrm{~mL})$. Organic phases were collected and solvent removed under vacuum. Conversions and yields were determined by GC using decane as internal standard. The obtained products were characterized by GC-MS and $\left({ }^{1} \mathrm{H}\right.$ and $\left.{ }^{13} \mathrm{C}\right)-\mathrm{NMR}$, and compared to the previously reported data.

\section{6. $\mathrm{ScCO}_{2}$ extractor}

A SEPAREX SF200 pilot (Separex Company, Nancy, France) was used to carry out the extraction (see Figure S1 1 in the Supporting Information). ${ }^{29}$ This apparatus consisted of a $200 \mathrm{~mL}$ contacting vessel that can be used as a reactor and/or liquid-fluid extractor. The introduction of $\mathrm{CO}_{2}$ was done through a filter mesh screen from a commercial HPLC pump. This device allowed good dispersion of $\mathrm{CO}_{2}$ in the glycerol-based mixture. Additionally, a magnetic stirrer was added to improve the dispersion. A cascade of three $20-\mathrm{mL}$ cyclonic separators was present at the outlet of the extractor. The pressure in each vessel was adjusted by depressurization valves. A volumetric pump (Milton Roy, flow rate maximum $5 \mathrm{~kg} / \mathrm{h}$ ) was used to pump subcooled $\mathrm{CO}_{2}$ in the system. The extractor was then heated to the desired temperature with a continuous flow of $\mathrm{CO}_{2}$. Experiments were carried out in open-loop or closed-loop configuration; in the latter case, $\mathrm{CO}_{2}$ was recycled at the head of the pump after condensation. Temperature and pressure were controlled 
in each unit of the pilot. The limitation of the pressure was $300 \pm 10$ bar and temperature was 80 $\pm 5^{\circ} \mathrm{C}$.

\section{Results and Discussion}

\subsection{Effect of $\mathrm{seCO}_{2}$ on the synthesis and catalytic behavior of PdNPs.}

In the absence of $\mathrm{scCO}_{2}$, our precedent works prove that glycerol favors the dispersion of MNPs but needs the presence of a stabilizer in order to avoid the aggregation. ${ }^{30-34}$ However, choline tosylalaninate /glycerol mixture is a solvent that also acts as nanoparticle stabilizer, leading to stable solutions of size-controlled metal nanoparticles ${ }^{26}$ in agreement with the modelling studies carried out by Atilhan and Aparicio. ${ }^{35}$ In the present study, we prepared PdNPs stabilized by choline tosylalaninate (IL) in glycerol under argon (PdA) following our previously reported methodology, ${ }^{26}$ and also in the presence of $\mathrm{scCO}_{2}(\mathbf{P d B})$ with the aim of studying the effect of $\mathrm{scCO}_{2}$ in the morphology of the as-prepared PdNPs (Figure 2). In both cases, black colloidal solutions were obtained, constituted of well-dispersed and small spherical nanoparticles (for PdA, $1.7 \pm 0.6 \mathrm{~nm}$; for $\mathbf{P d B}, 1.3 \pm 0.3 \mathrm{~nm}$ ) as evidenced by TEM, being PdNPs prepared under $\mathrm{scCO}_{2}$ (PdB) clearly smaller than those prepared in its absence (PdA). Hence, the $\mathrm{scCO}_{2} /$ glycerol/IL tricomponent medium was probably less viscous than that glycerol/IL di-component solvent, mainly due to the enhanced solubility of $\mathrm{CO}_{2}$ in the glycerol and IL mixture, ${ }^{36}$ triggering a better diffusion of the metal precursor $\left[\mathrm{PdCl}_{2}(\operatorname{cod})\right]$ (cod $=$ cycloocta-1,5-diene). This effect leads to a homogeneous dispersion of $\mathrm{Pd}$ nuclei (generated by reduction of $\mathrm{Pd}(\mathrm{II})$ molecular species by glycerol), favoring a more uniform growth of these nanoclusters, in agreement with the relative narrow size distribution of nanoparticles observed under $\mathrm{scCO}_{2}(1.3 \pm 0.3 \mathrm{~nm}$ for $\mathbf{P d B}$ vs $1.7 \pm 0.6$ $\mathrm{nm}$ for PdA). In addition, intermolecular interactions between $\mathrm{CO}_{2}$ and glycerol/IL mixture can 
modify the supramolecular arrangement of the medium at least at nanoscopic level (probably no long-range effects are induced), ${ }^{37,38}$ most likely causing an impact on the growth of MNP by confinement effect of PdNPs; actually, smaller size of PdNPs was obtained in the presence of $\mathrm{scCO}_{2}$ than in its absence $\left(\mathrm{d}_{\text {mean }}=1.3 \mathrm{~nm}\right.$ for $\mathbf{P d B} v s \mathrm{~d}_{\text {mean }}=1.7 \mathrm{~nm}$ for $\left.\mathbf{P d A}\right)$.
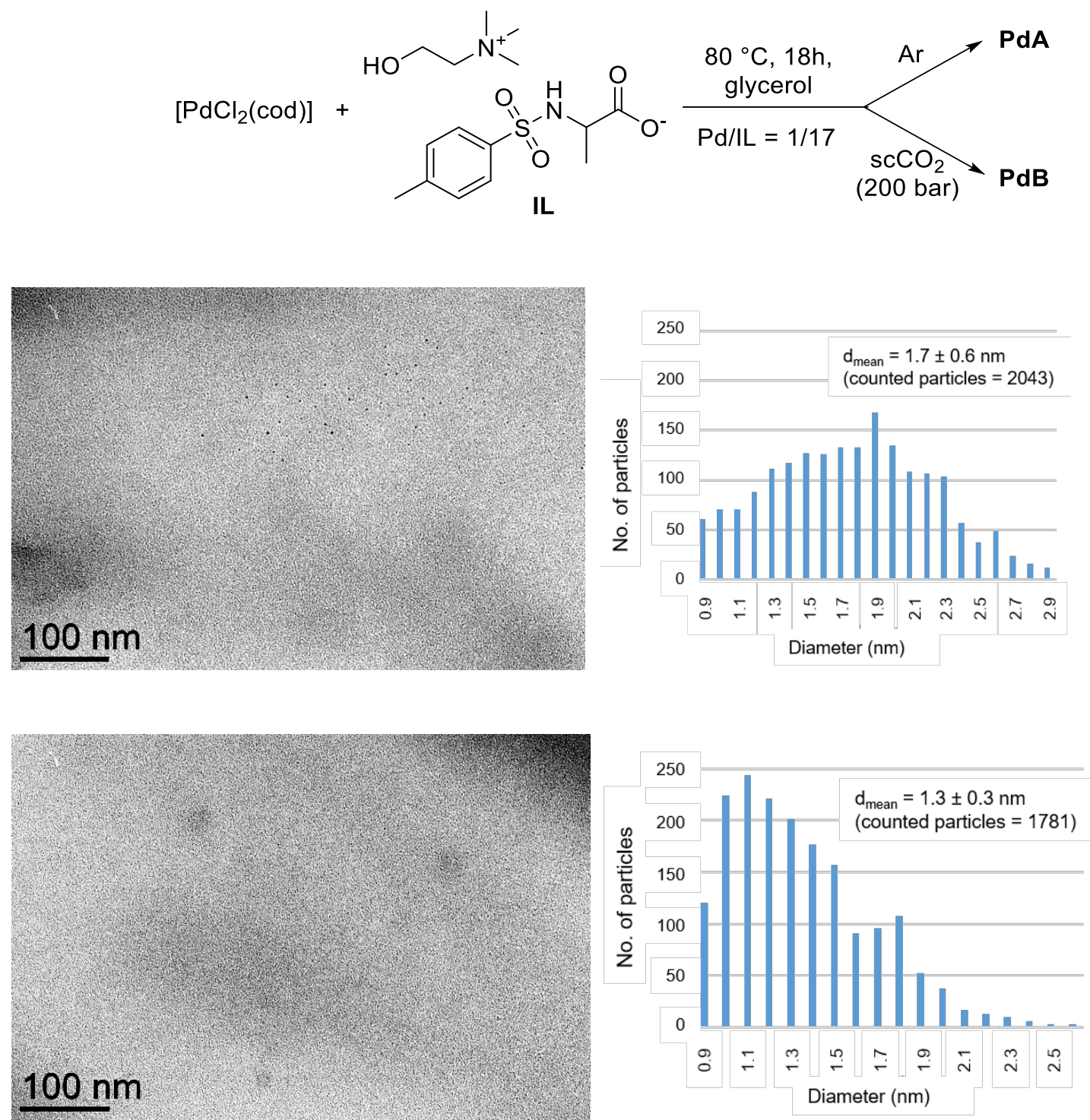

Figure 2. Synthesis of PdNPs under argon $(\mathbf{P d A})^{26}$ or under $\mathrm{scCO}_{2}(\mathbf{P d B})$ (top). TEM images in glycerol for PdA (middle) and PdB (bottom) with the corresponding size distribution diagram. 
The effect of metal nanoparticles size on catalytic hydrogenation reactions has been extensively studied..$^{39}$ The well-controlled synthesis of MNPs in terms of morphology and surface state permits to tune the reactivity of MNPs, leading to selective processes when poly-functional substrates are considered. ${ }^{40}$ It is important to note that for the as-prepared nanoparticles, the difference in size is significant. For PdA, the most population of nanoparticles are ca. $1.9 \mathrm{~nm}$; for PdB, ca. $1.1 \mathrm{~nm}$ (Figure 2). Considering a fcc structure of spherical nanoparticles, ${ }^{26}$ PdNPs exhibiting a mean diameter of ca. $1.1 \mathrm{~nm}$ represents ca. $76 \%$ of total atoms at the surface, while for PdNPs showing a mean diameter of ca. $2.0 \mathrm{~nm}, 52 \%$ of total atoms are at the surface, clearly decreasing the number of active sites.

With the purpose of evaluating the catalytic behavior of PdA and PdB, we chose 4-phenylbut3-en-2-one (1) due to the presence on the same substrate of different unsaturated groups prone to be reduced $\left(\mathrm{C}=\mathrm{O}, \mathrm{C}=\mathrm{C}\right.$, aromatic ring). The reactions were carried out under 20 bar of $\mathrm{H}_{2}$ at $80{ }^{\circ} \mathrm{C}$ for $18 \mathrm{~h}$, using $1 \mathrm{~mol} \% \mathrm{Pd}$ (Table 1 ). In contrast to non-aromatic $\mathrm{C}=\mathrm{C}$ bonds, carbonyl groups are more demanding to be hydrogenated with Pd-based catalysts. ${ }^{26,41}$ Under these conditions both catalysts gave full conversion, obtaining a mixture of 4-phenylbutan-2-one (1a) and 4phenylbutan-2-ol (1b). PdB led to a higher amount of $\mathbf{1 b}$ than $\mathbf{P d A}$ (entry 2 vs 1, Table 1), pointing to its higher reactivity towards the reduction of the carbonyl group. Thus, smaller nanoparticles exhibited higher activity (PdA $v s \mathbf{P d B}$, see above Figure 2). This behavior can be explained by the fact that $\mathrm{C}=\mathrm{C}$ are hydrogenated on the faces of PdNPs (favored for larger PdNPs ${ }^{42}$ ) while for the activation of $\mathrm{C}=\mathrm{O}$ group, palladium atoms exhibiting more electrophilic character are needed, ${ }^{43}$ being those occupying sites with low coordination number (such as edges and vertexes); the relative atoms in these latter positions decrease with the increase of PdNPs size. 
Table 1. Hydrogenation of 4-phenylbut-3-en-2-one (1) catalyzed by $\mathbf{P d A}$ and $\mathbf{P d B}{ }^{a}$

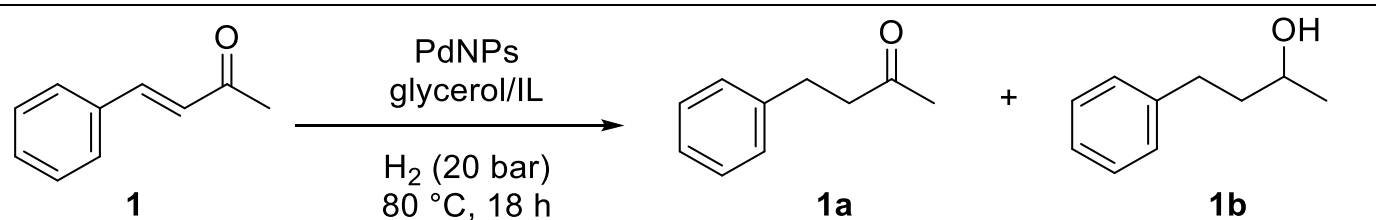

1

$80^{\circ} \mathrm{C}, 18 \mathrm{~h}$

$1 \mathrm{a}$

$1 \mathrm{~b}$

\begin{tabular}{|c|c|c|c|c|}
\hline \multirow[t]{2}{*}{ Entry } & \multirow[t]{2}{*}{ Catalyst $(\mathrm{PdNPs})^{b}$} & \multirow{2}{*}{$\begin{array}{c}\text { Conv. }^{c}(\%) \\
{[\mathrm{TON}]^{d}}\end{array}$} & \multicolumn{2}{|c|}{ Selectivity $^{d}(\%)$} \\
\hline & & & $\mathbf{1 a}$ & $1 \mathrm{~b}$ \\
\hline 1 & $\operatorname{PdA}$ & $\begin{array}{c}100 \\
{[100]}\end{array}$ & 82 & 18 \\
\hline 2 & PdB & $\begin{array}{c}100 \\
{[100]}\end{array}$ & 65 & 35 \\
\hline
\end{tabular}

$\overline{{ }^{a}}$ Results from duplicated experiments. Reaction conditions: $1 \mathrm{mmol}$ of $\mathbf{1}$ and $1 \mathrm{~mL}$ of the corresponding catalytic solution of PdA or PdB $\left(10^{-2} \mathrm{~mol} \mathrm{~L}^{-1}, 0.01 \mathrm{mmol}\right.$ of total $\left.\mathrm{Pd}\right), 80{ }^{\circ} \mathrm{C}$ for 18 h. ${ }^{b}$ See Figure 2 for the synthesis of PdNPs in glycerol/IL. ${ }^{d}$ Determined by GC using decane as internal standard. ${ }^{d}$ TON calculated as the ratio between converted mol of $\mathbf{1}$ and mol of total Pd (converted mol of $\mathbf{1} / \mathrm{mol}$ of total Pd).

After catalysis, the extraction of organic products was carried out by a biphasic system using a non-miscible organic solvent with glycerol like dichloromethane, cyclohexane, ethyl acetate or heptane. With the purpose of replacing the use of volatile organic solvents, we were also interested in the extraction process using $\mathrm{scCO}_{2}$, as well-known for the extraction of different organic compounds. ${ }^{44-47} \mathrm{We}$ carried out the hydrogenation of 4-phenylbut-3-en-2-one under reaction conditions which permit the exclusive reduction of the $\mathrm{C}=\mathrm{C}$ bond by working at lower 
pressure, only obtaining 4-phenylbutan-2-one (see Scheme S2 in the Supporting Information). The extraction of 4-phenylbutan-2-one from the catalytic mixture using $\mathrm{scCO}_{2}$ was successfully carried out with the SEPAREX extractor (see above, section 2), obtaining up to $90 \%$ of 1a at 200 bar of $\mathrm{CO}_{2}$ and $60{ }^{\circ} \mathrm{C}$. In the extracted product, neither leaching of Pd (checked by ICP-AES) nor extraction of glycerol or IL (checked by NMR) were detected, in agreement with the known low solubility of glycerol in $\mathrm{scCO}_{2} \cdot{ }^{36,48}$ Additionally, TEM analysis of the PdNPs after $\mathrm{scCO}_{2}$ extraction showed a very good dispersion without any sign of agglomeration, preserving the mean size ( $1.6 \pm 0.5 \mathrm{~nm}$ for 1799 particles $)$ compared to the PdNPs before being used in catalysis $(1.7 \pm$ $0.6 \mathrm{~nm}$, see Figure 2), in accordance with the beneficial effect of $\mathrm{scCO}_{2}$ in the dispersion of PdNPs (see Figure S12 in the Supporting Information). ${ }^{49}$ This behavior permits to envisage a plausible recycling of the catalytic phase, study that is outside the scope of this work.

With the aim of increasing the solubility of $\mathrm{H}_{2}$ in the choline IL/glycerol medium, the challenging hydrogenation of the $\mathrm{C}=\mathrm{O}$ bond of the ketone 1a was carried out in the presence of $\mathrm{CO}_{2}$ (Table 2), known as carrier of $\mathrm{H}_{2}$ in different media. ${ }^{5-52}$ In the absence of $\mathrm{CO}_{2}$, up to $40 \%$ conversion was reached under 40 bar $\mathrm{H}_{2}$ (entry 2, Table 2); only $23 \%$ conversion under 20 bar $\mathrm{H}_{2}$ (entry 1, Table 2). The benefic effect of $\mathrm{CO}_{2}$ could clearly be stated when the reaction was carried out under the same total pressure (40 bar) but using four times less amount of $\mathrm{H}_{2}$ (entry 2 vs 3 , Table 2), evidencing that $\mathrm{CO}_{2}$ increased the efficiency of the hydrogenation reaction. However, conversion could not be increased beyond $40 \%$ even at higher pressures (entry 4 , Table 2). The reason behind this behavior might be the catalyst deactivation after a certain time, probably due to CO metal surface poisoning, which can be generated as consequence of the reverse water-gas shift reaction. ${ }^{53,54}$ 
Table 2. Hydrogenation of 4-phenylbutan-2-one in glycerol catalyzed by $\mathbf{P d A}$ in the presence of $\mathrm{CO}_{2}{ }^{a}$

\begin{tabular}{|c|c|c|c|}
\hline & $1 a$ & $\begin{array}{c}\mathrm{PdA}(1 \mathrm{~mol} \%) \\
\mathrm{H}_{2}, \mathrm{CO}_{2} \\
\underset{\text { glycerol//L }}{ } \\
80^{\circ} \mathrm{C}, 18 \mathrm{~h}\end{array}$ & $\mathrm{OH}^{\mathrm{OH}}$ \\
\hline Entry & $\begin{array}{l}p\left(\mathrm{H}_{2}\right) \\
\text { (bar) }\end{array}$ & $\begin{array}{c}p\left(\mathrm{CO}_{2}\right) \\
\text { (bar) }\end{array}$ & $\begin{array}{c}\text { Conv. (yield) }{ }^{b}(\%) \\
{[\mathrm{TON}]^{c}}\end{array}$ \\
\hline 1 & 20 & 0 & $\begin{array}{c}23(20) \\
{[23]}\end{array}$ \\
\hline 2 & 40 & 0 & $\begin{array}{c}40(37) \\
{[40]}\end{array}$ \\
\hline 3 & 10 & 30 & $\begin{array}{c}44(42) \\
{[44]}\end{array}$ \\
\hline 4 & 40 & 40 & $\begin{array}{c}45(43) \\
{[45]}\end{array}$ \\
\hline
\end{tabular}

\footnotetext{
${ }^{a}$ Results from duplicated experiments. Reaction conditions: $1 \mathrm{mmol}$ of $1 \mathrm{a}$ and $1 \mathrm{~mL}$ of the corresponding catalytic glycerol solution of PdNPs $\left(10^{-2} \mathrm{~mol} \mathrm{~L}^{-1}, 0.01 \mathrm{mmol}\right.$ of total Pd). ${ }^{b}$ Determined by GC using decane as internal standard. ${ }^{c}$ TON calculated as the ratio between converted mol of $\mathbf{1}$ and mol of total Pd (converted mol of $\mathbf{1} / \mathrm{mol}$ of total Pd).
} 


\subsection{Rationalization of $\mathrm{CO}_{2}$ effect in choline tosylalaninate/glycerol system.}

Viscosity is one of the key parameters that controls the diffusion rate of molecular species in a solvent medium and hence affects the reaction rates of diffusion-controlled processes on the microscopic level. ${ }^{25}$ Molecular rotors have emerged as one the most innovative methods to measure the viscosity at the micro-scale. ${ }^{23-25}$ Artificial molecular rotors, inspired in natural motor proteins, are "molecular machines" capable of continuous directional motions under an energy input. ${ }^{55}$ In particular, in the case of fluorescent molecular rotors (FMR), the rotation of bonds linked to a fluorescent $\pi$-conjugated moiety is overcome by increasing the viscosity of the reaction medium, triggering a fluorescence intensity increase ${ }^{56,57}$ One of the most commonly known FMR is DCVJ. Reed et al. have described DCVJ as a fluorescent dye whose intramolecular rotational relaxation depends on the nature of the solvent. ${ }^{58,59}$ Intramolecular rotation caused within the FMR is governed by the molecular-free volume of the solvent; in general, the higher the viscosity, the smaller molecular-free volume, hence the fluorescence intensity increases. ${ }^{60}$

In this part of the study, an effort has been made to rationalize the role of $\mathrm{CO}_{2}$ in the choline tosylalaninate/glycerol/ $\mathrm{CO}_{2}$ system in order to understand its effect on the synthesis of PdNPs and its improved catalytic activity as well as in the extraction of products by using $\mathrm{scCO}_{2}$. Some of these queries can be answered by understanding the mass transfer and diffusion properties of various compounds in choline tosylalaninate/glycerol mixture.

For that, viscosity of the choline tosylalaninate/glycerol with increasing amounts of $\mathrm{CO}_{2}$ was studied. We implemented a method used in the literature by using fluorescent molecular rotors to determine the viscosity of the system. ${ }^{28,61,62}$ We used two molecular rotors (Figure 1), being DCVJ 
our benchmark molecule. Figure 3 collects the values of viscosity measured by using DCVJ at 60 ${ }^{\circ} \mathrm{C}$ and $80{ }^{\circ} \mathrm{C}$.
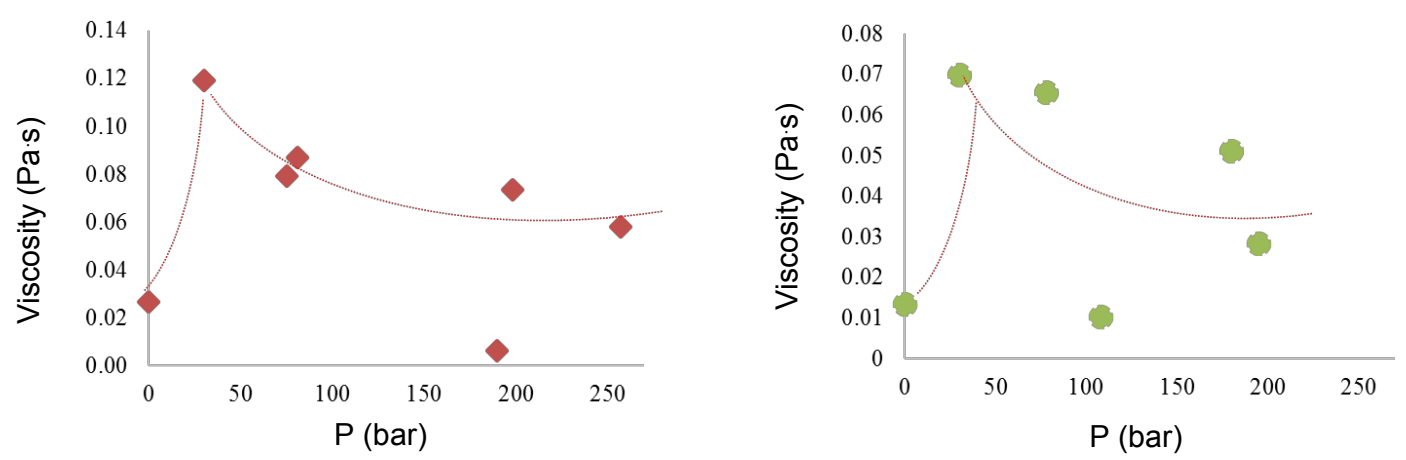

Figure 3. Viscosity measurements of choline tosylalaninate/glycerol mixture (1/100) using DCVJ as molecular rotor at $60^{\circ} \mathrm{C}$ (left) and $80^{\circ} \mathrm{C}$ (right).

As reported in the literature for liquids in general, ${ }^{13,63-65}$ a monotonous decrease in viscosity of the DES (choline tosylalaninate/glycerol mixture with a 1/100 ratio) was expected by increasing $\mathrm{CO}_{2}$ pressure. However, we observed an increase in the viscosity at pressures lower than 50 bar and a viscosity decrease at higher pressures. Data presented in Figure 3 shows an increase of viscosity at pressures up to 50 bar; these observations are in accordance with previous measurements of viscosity in DES. ${ }^{66}$ In our study, viscosity reaches a maximum at 50 bar after which a clear decrease could be observed; this trend is observable at both temperatures studied.

The behavior of viscosity as function of $\mathrm{CO}_{2}$ pressure can be explained in terms of the high excess molar volume $\left(\mathrm{V}_{\mathrm{m}}{ }^{\mathrm{E}}\right)$ of the solution, which is the difference between the molar volume $\left(V_{m}\right)$ and the ideal volume $\left(V_{m}^{\text {ideal }}\right)$ of the mixture DES- $\mathrm{CO}_{2}$, and the high increase in density of the system, at some concentrations of $\mathrm{CO}_{2}$. V. A. Bloomfield and R. K. Dewan have related the free excess volume of mixing to the viscosity through equation 2 (for a detailed treatment of thermodynamic equations, see references ${ }^{67}$ and $^{68}$ ): 


$$
\Delta \ln \eta=f(v)-\frac{\Delta G^{R}}{R T}
$$

where $\Delta \ln \eta$ refers to viscosity deviations from ideal behavior, $f(v)$ is a characteristic function of the free volume, and $\Delta \mathrm{G}^{\mathrm{R}}$ is the residual energy of mixing which is closely related to the excess energy of mixing and the molar volumes of the compounds in the mixture ( $\mathrm{R}$ represents the ideal gas constant and $\mathrm{T}$, the temperature). Thus, free volume and viscosity are closely and related through the energy of mixing; from this equation an inflection point is possible if the second part of the equation becomes greater than the first.

Furthermore, and according to the Prigogine-Flory-Patterson (PFP) theory, three contributions to the excess volume of mixing can be taken into consideration: i) interactional $\left(V_{m_{\text {inter }}}^{E}\right)$, ii) free volume contribution $\left(V_{m_{\text {free vol }}}^{E}\right)$, and iii) differences of internal pressures and differences of reduced volumes of the components $\left(V_{m_{P *}}^{E}\right)$, the $\mathrm{P}^{*}$ parameter corresponds to the internal pressure contribution (eq. 3). Equation 4 permits to calculate $V_{m}{ }^{E}$ from density of the system $(\rho)$, densities of both compounds present in the solution, $\rho_{1}$ and $\rho_{2}$ respectively, and molecular weight of both compounds, $M_{1}$ and $M_{2}$ respectively.

$$
\begin{aligned}
& V_{m}^{E}=V_{m_{\text {inter }}}^{E}+V_{m_{\text {free vol }}}^{E}+V_{m_{P *}}^{E} \\
& V_{m}^{E}=V_{m}-V_{m}^{\text {ideal }}=\frac{x_{1} M_{1}+x_{2} M_{2}}{\rho}-\left[\frac{x_{1} M_{1}}{\rho_{1}}+\frac{x_{2} M_{2}}{\rho_{2}}\right]
\end{aligned}
$$

By analyzing equation 4, a qualitative analysis can be done as $V_{m}{ }^{E}$ can change from negative to positive values if density of one of the compounds becomes high enough; the second part of the equation becomes then smaller than the first part, which can happen at high pressures of $\mathrm{CO}_{2}$ at different temperatures (see Figure S13 in the Supporting Information) ${ }^{69}$ Change of $V_{m}^{E}$ values from 
negative to positive denotes the inflection in the behavior of viscosity, from increase to decrease of this property. From a physicochemical point of view, a negative $V_{m}^{E}$ comes from two phenomena: a) mixtures of compounds (such as a DES) exhibit stronger intermolecular interactions than neat molecular compounds; and b) $\mathrm{CO}_{2}$ molecules fills interstitial free volume of the liquid phase increasing the density of the system, suggesting the formation of clusters in the DES- $\mathrm{CO}_{2}$ mixture at low concentrations of $\mathrm{CO}_{2}$. A similar behavior of $V_{m}^{E}$ with the concentration of one of the components has previously been reported for systems constituted of [BMIM] $\left.\mathrm{PF}_{6}\right]-$ EGMME (BMIM = 1-buty-3-methyl imidazolium; EGMME = ethylene glycol monomethyl ether) at different temperatures. Actually, PFP theory accurately predicts this behavior in particular for Ionic Liquids-EGMME systems, ${ }^{66}$ while the Perturbed Chain Statistical Associating Fluid Theory (PC-SAFT) equation of state used in combination of Free Volume Theory has been successfully used to describe the increase in viscosity of choline chloride-based DES with different hydrogen bond donor partners such as ethylene glycol, glycerol or urea. ${ }^{70}$

Some authors have proposed the filling of free volume between molecules of DES by $\mathrm{CO}_{2}$, which would hinder mass transfer, increasing viscosity followed by a decrease in viscosity when free volume is completely filled and $\mathrm{CO}_{2}$ continues to be added. ${ }^{63,71}$ Furthermore, Luo et al. explained that due to the formation of hydrogen bonds during $\mathrm{CO}_{2}$ captured by amino-tailored cation, an increase in viscosity can be observed. ${ }^{72}$ In our case, this behavior was observed with the two molecular rotors used in this study. Figure 4 shows the measurement of viscosity using a BODIPY-MR (see above Figure 1). With this data, it is clearly proven that the viscosity of the choline tosylalaninate/glycerol mixture decreases with increasing $\mathrm{CO}_{2}$ pressure. These results help us to understand the mass transfer behavior of the system. 

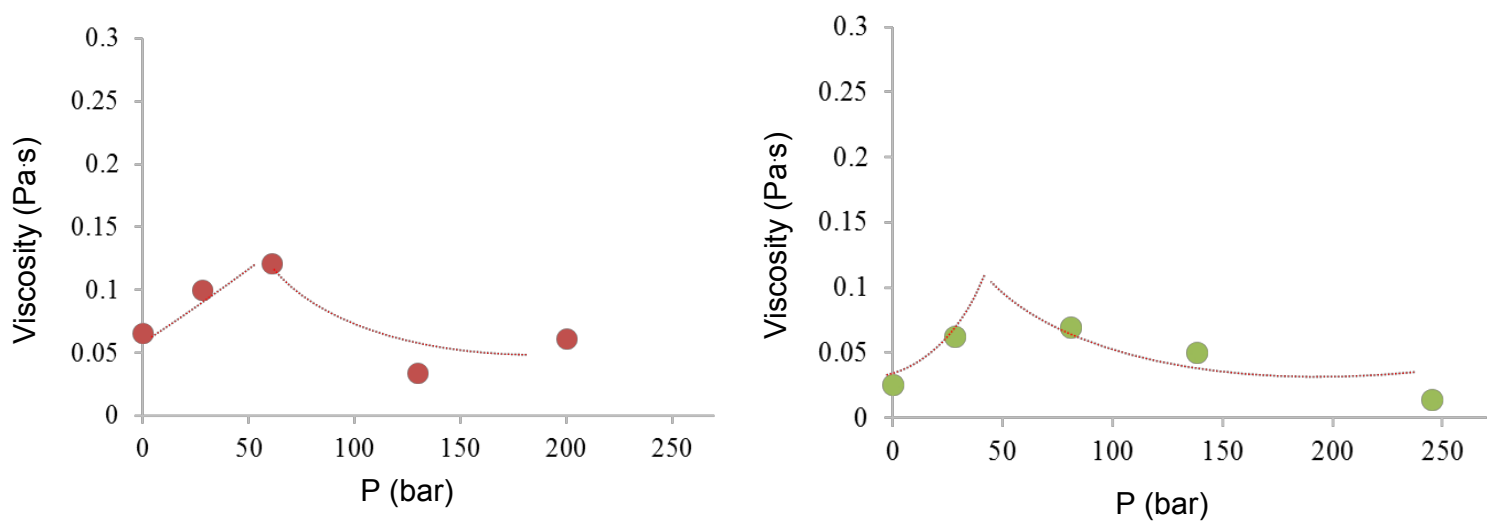

Figure 4. Viscosity measurements of choline tosylalaninate/glycerol mixture (1/100) by using BODIPY-MR as molecular rotor at $60{ }^{\circ} \mathrm{C}$ (left) and $80{ }^{\circ} \mathrm{C}$ (right), as function of $\mathrm{CO}_{2}$ pressure.

Moreover, diffusion constants (D) of 1 (4-phenylbut-3-en-2-one) and 1a (4-phenylbutane-2one) in the glycerol/choline tosylalaninate $/ \mathrm{CO}_{2}$ mixture at $80{ }^{\circ} \mathrm{C}$ with increasing pressures, were calculated (Figure 5). The diffusion constant is a crucial thermodynamic property to be considered for the extraction of solutes. ${ }^{73}$ In this work, diffusion constants were calculated using the StokesEinstein equation (eq. 5). ${ }^{74}$

$$
D=\frac{k_{B} T}{6 \pi \eta r}
$$

where, $\mathrm{k}_{\mathrm{B}}$ is the Boltzmann constant $\left(1.38 \times 10-23 \mathrm{~m}^{2} \mathrm{~kg} \mathrm{~s}^{-2} \mathrm{~K}^{-1}\right)$, $\mathrm{T}$ is the temperature in $\mathrm{K}, \eta$ is the viscosity (values taken from the data obtained from measurements with molecular rotors), and $\mathrm{r}$ is defined as the radius of a sphere of volume equal to the van der Waals volume of the diffusing molecule; $r$ was calculated using the Bondi method described by Zhao et al. ${ }^{75}$ 

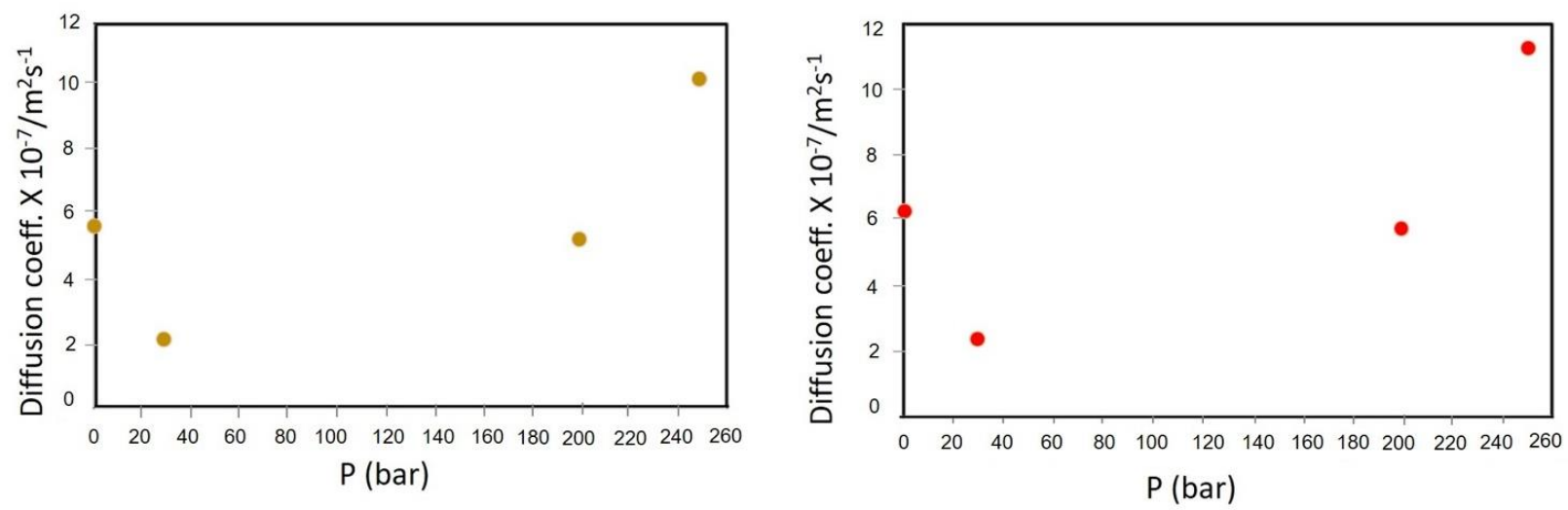

Figure 5. Diffusion constant of 1 (left) and 1a (right) in choline tosylalaninate/glycerol/ $/ \mathrm{CO}_{2}$ mixture $(1$ or $1 \mathbf{a} /$ choline tosylalaninate/glycerol $)$ at $80{ }^{\circ} \mathrm{C}$.

We also calculated the diffusion constant of $\mathrm{H}_{2}$ in the medium at $60{ }^{\circ} \mathrm{C}$ and at $80{ }^{\circ} \mathrm{C}$ (Figure 6). According to our results, the decrease in viscosity of the solvent medium increased the diffusion constants of organic compounds $(\mathbf{1}, \mathbf{1 a})$ and $\mathrm{H}_{2}$, which favors the increase of $\mathrm{H}_{2}$ solubility. These physico-chemical data may explain the results obtained when $\mathrm{CO}_{2}$ was used in the catalytic hydrogenation of $\mathbf{1}$ (Table 2), observing a higher catalytic activity when $\mathrm{CO}_{2}$ was present (entry 3 , Table 2). Furthermore, the use of $\mathrm{CO}_{2}$ permitted to decrease the partial pressure of $\mathrm{H}_{2}$ used for the hydrogenation reactions (entry 3 s 2 , Table 2). 

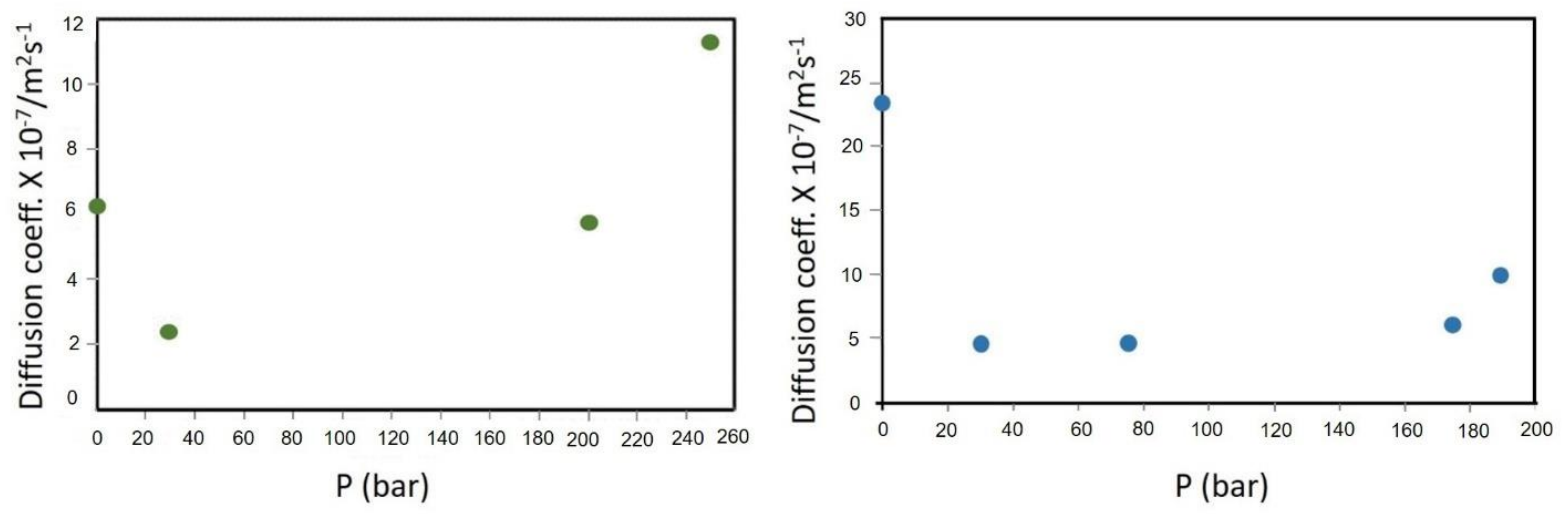

Figure 6. Diffusion constants of $\mathrm{H}_{2}$ in the reacting medium at $60{ }^{\circ} \mathrm{C}$ (left) and $80{ }^{\circ} \mathrm{C}$ (right).

\section{Conclusions}

To sum up, in this work, we conceived a new catalytic system constituted of small palladium nanoparticles homogeneously dispersed in a choline tosylalaninate/glycerol $/ \mathrm{scCO}_{2}$ mixture, in the absence of any other nanoparticle stabilizer, proving its efficiency in hydrogenation processes. These PdNPs exhibited higher catalytic activity than those prepared in the absence of $\mathrm{scCO}_{2}$ in hydrogenation reactions, probably due to their smaller size (1.7 nm vs $1.3 \mathrm{~nm}$ for PdNPs prepared in choline tosylalalinate/glycerol and choline tosylalalinate/glycerol $/ \mathrm{scCO}_{2}$ mixture, respectively). Moreover, extraction of organic products from the choline tosylalalinate/glycerol/PdNPs catalytic system was successfully carried out by using $\mathrm{scCO}_{2}$, without addition of any volatile organic cosolvent.

Furthermore, when hydrogenation reactions were carried out in the presence of $\mathrm{CO}_{2}$, a beneficial effect was observed. With the aim of rationalizing this behavior, we carried out a study concerning both viscosity and mass transfer. Concerning viscosity, we could prove the efficiency of fluorescent molecular rotors used as viscosity probes in environments where measurements by mechanical rheometers are complicated or expensive. We used two molecular rotors, i.e. DCVJ 
(commercially available, used as benchmark rotor) and BODIPY-MR (new molecular rotor prepared by a multi-step methodology). Although these rotors exhibit a different backbone and functionalization, both presented the same tendency: when $\mathrm{CO}_{2}$ pressure was increased up to $c a$. 50 bar, viscosity increased; under higher pressure, a decrease in viscosity by half was observed. This behavior is in accordance with other reported studies concerning DES in contact with $\mathrm{CO}_{2} .{ }^{66}$ In the same sense, calculations concerning diffusion coefficients of $\mathrm{H}_{2}$ and reactants in the catalytic medium indicated that diffusion increased to values of almost twice in relation to the initial values, due to the viscosity decrease of the medium.

In conclusion, we determined the micro-viscosity for a complex catalytic system in the presence of $\mathrm{CO}_{2}$ pressure and thus rationalized its catalytic behavior. We observed a viscosity decrease of the medium at high pressures; this effect triggered an increase of the diffusion coefficients of reactants and consequently a better efficiency of the catalytic system.

\section{Acknowledgments}

The Université Fédérale de Toulouse (program IDEX Recherche - Actions Thématiques Stratégiques), the Centre National de la Recherche Scientifique (CNRS) and the Université Toulouse 3-Paul Sabatier are gratefully acknowledged for their financial support. A. M.-B. thanks the Ministerio de Economía y Competitividad and AEI/FEDER UE (CTQ2016-75016-R) and Departament d'Economia i Coneixement (2017 SGR 1472) for the financial support. N. F. acknowledges financial support from CONACYT, PAIP and PAPIIP IN222819. Authors greatly acknowledge Severine Camy for her help on extraction experiments, Christian Pradel for TEM analyses and Isabelle Favier for her assistance in hydrogenation reactions. G. G. thanks Université Fédérale de Toulouse for PhD scholarship through the IDEX program. 


\section{ASSOCIATED CONTENT}

Supporting Information. The following files are available free of charge: Table S1; Schemes S1-S2; Figures S1-S13; synthesis and characterization of intermediates for the synthesis of

BODIPY-MR; characterization of organic products obtained in hydrogenation reactions and temperatures.

\section{AUTHOR INFORMATION}

\section{Corresponding Authors}

*Authors to whom correspondence should be addressed. Electronic mail:

yaocihuatl.medinagonzalez-ext@,solvay.com, gomez@,chimie.ups-tlse.fr

\section{ORCID}

Anna M. Masdeu-Bultó: 0000-0001-7938-3902

Norberto Farfán: 0000-0003-4320-2975

Javier Ordóñez-Hernández: 0000-0002-7720-3442

Montserrat Gómez: 0000-0003-1211-1333

Yaocihuatl Medina-Gonzalez: 0000-0003-2859-8158

\section{Present Addresses}

$\dagger$ Centre National de Recherche Scientifique, University of Bordeaux, Solvay, LOF, UMR 5258

CNRS Solvay, 33600 Pessac, France

\section{Author Contributions}

The manuscript was written through contributions of all authors. All authors have given approval to the final version of the manuscript. 


\section{Funding Sources}

The Université Fédérale de Toulouse (program IDEX Recherche - Actions Thématiques Stratégiques), the Centre National de la Recherche Scientifique (CNRS), the Université Toulouse 3-Paul Sabatier, the Ministerio de Economía y Competitividad and AEI/FEDER UE (CTQ2016-75016-R), the Departament d'Economia i Coneixement (2017 SGR 1472) and the Consejo Nacional de Ciencia y Tecnología (CONACYT).

\section{REFERENCES}

(1) Hitzler, M. G.; Smail, F. R.; Ross, S. K.; Poliakoff, M. Selective Catalytic Hydrogenation of Organic Compounds in Supercritical Fluids as a Continuous Process. Org. Process Res. Dev. 1998, 2, 137-146. https://doi.org/10.1021/op970056m.

(2) G. Hitzler, M.; Poliakoff, M. Continuous Hydrogenation of Organic Compounds in Supercritical Fluids. Chem. Commun. 1997, 1667-1668. https://doi.org/10.1039/A704371F.

(3) More, S. R.; Yadav, G. D. Effect of Supercritical $\mathrm{CO}_{2}$ as Reaction Medium for Selective Hydrogenation of Acetophenone to 1-Phenylethanol. ACS Omega 2018, 3, 7124-7132. https://doi.org/10.1021/acsomega.8b00001.

(4) Aymonier, C.; Philippot, G.; Erriguible, A.; Marre, S. CHAPTER 10: Materials Processing and Recycling with Near-and Supercritical $\mathrm{CO}_{2}$-Based Solvents; Attard, T. M.; Hunt, A. J., Ed.; Royal Society of Chemistry: Cambridge, 2018. https://doi.org/10.1039/9781788013543-00304.

(5) Zhang, X.; Heinonen, S.; Levänen, E. Applications of Supercritical Carbon Dioxide in Materials Processing and Synthesis. RSC Adv. 2014, 4, 61137-61152. https://doi.org/10.1039/c4ra10662h. 
(6) Wang, Q.; Cheng, H.; Liu, R.; Hao, J.; Yu, Y.; Zhao, F. A Green and Efficient Route for Preparation of Supported Metal Colloidal Nanoparticles in $\mathrm{ScCO}_{2}$. Green Chem. 2010, 12, 1417-1422. https://doi.org/10.1039/c004647g.

(7) Erkey, C. Preparation of Metallic Supported Nanoparticles and Films Using Supercritical Fluid Deposition. J. Supercrit. Fluids 2009, 47, 517-522. https://doi.org/10.1016/j.supflu.2008.10.019.

(8) Hu, D.; Xu, H.; Yi, Z.; Chen, Z.; Ye, C.; Wu, Z.; Garces, H. F.; Yan, K. Green $\mathrm{CO}_{2}$-Assisted Synthesis of Mono- and Bimetallic Pd/Pt Nanoparticles on Porous Carbon Fabricated from Sorghum for Highly Selective Hydrogenation of Furfural. ACS Sustain. Chem. Eng. 2019, 7, 15339-15345. https://doi.org/10.1021/acssuschemeng.9b02665.

(9) Qiao, Y.; Said, N.; Rauser, M.; Yan, K.; Qin, F.; Theyssen, N.; Leitner, W. Preparation of SBA-15 Supported Pt/Pd Bimetallic Catalysts Using Supercritical Fluid Reactive Deposition: How Do Solvent Effects during Material Synthesis Affect Catalytic Properties? Green Chem. 2017, 19, 977-986. https://doi.org/10.1039/C6GC02490D.

(10) Shah, P. S.; Holmes, J. D.; Doty, R. C.; Johnston, K. P.; Korgel, B. A. Steric Stabilization of Nanocrystals in Supercritical $\mathrm{CO}_{2}$ Using Fluorinated Ligands. J. Am. Chem. Soc. 2000, 122, 4245-4246. https://doi.org/10.1021/ja9943748.

(11) McLeod, M. C.; Gale, W. F.; Roberts, C. B. Metallic Nanoparticle Production Utilizing a Supercritical Carbon Dioxide Flow Process. Langmuir 2004, 20, 7078-7082. https://doi.org/10.1021/la0493262.

(12) Chih, Y. W.; Cheng, W. T. Supercritical Carbon Dioxide-Assisted Synthesis of Silver 
Nano-Particles in Polyol Process. Mater. Sci.Eng. B Solid-State Mater. Adv. Technol. 2007, 145, 67-75. https://doi.org/10.1016/j.mseb.2007.10.006.

(13) Jessop, P. G.; Subramaniam, B. Gas-Expanded Liquids. Chem.Rev. 2007, 107, 2666-2694. https://doi.org/10.1021/cr040199o.

(14) Subramaniam, B. Gas-Expanded Liquids for Sustainable Catalysis and Novel Materials: Recent Advances. Coord. Chem. Rev. 2010, 254, 1843-1853. https://doi.org/10.1016/j.ccr.2009.12.009.

(15) Xiang, H. M.; Sun, J. F.; Li, G.; Xu, Q. Q.; Li, Z. J.; Qiao, G. Y.; Yin, J. Z. Enhancement of a Double Cosolvent on Solubility of $[\mathrm{Bmim}][\mathrm{Ac}]$ and $[\mathrm{Bmim}]\left[\mathrm{NTf}_{2}\right]$ in Supercritical CO 2. J. Chem. Eng. Data 2020, 65, 1655-1662. https://doi.org/10.1021/acs.jced.9b01044.

(16) Wu, W.; Zhang, J.; Han, B.; Chen, J.; Liu, Z.; Jiang, T.; He, J.; Li, W. Solubility of RoomTemperature Ionic Liquid in Supercritical $\mathrm{CO}_{2}$ with and without Organic Compounds. Chem. Commun. 2003, 3, 1412-1413. https://doi.org/10.1039/b302311g.

(17) Handy, S. H. E.-S. Deep Eutectic Solvents in Organic Synthesis; IntechOpen: Rijeka, 2015. https://doi.org/10.5772/59254.

(18) Zhang, Q.; De Oliveira Vigier, K.; Royer, S.; Jérôme, F. Deep Eutectic Solvents: Syntheses, Properties and Applications. Chem. Soc. Rev. 2012, 41, 7108-7146. https://doi.org/10.1039/C2CS35178A.

(19) Meric, P.; Yu, K. M. K.; Tsang, S. C. Micelle-Hosted Palladium Nanoparticles Catalyze Citral Molecule Hydrogenation in Supercritical Carbon Dioxide. Langmuir 2004, 20, 85378545. https://doi.org/10.1021/la049549s. 
(20) Meric, P.; Yu, K. M. K.; Kong, A. T. S.; Tsang, S. C. Pressure-Dependent Product Distribution of Citral Hydrogenation over Micelle-Hosted Pd and Ru Nanoparticles in Supercritical Carbon Dioxide. J. Catal. 2006, 237, 330-336.

(21) Yeung, L. K.; Lee, C. T., Jr.; Johnston, K. P.; Crooks, R. M. Catalysis in Supercritical CO 2 Using Dendrimer-Encapsulated Palladium Nanoparticles. Chem. Commun. 2001, 22902291. https://doi.org/10.1039/b106594g.

(22) Liu, R.; Wu, C.; Wang, Q.; Ming, J.; Hao, Y.; Yu, Y.; Zhao, F. Selective Hydrogenation of Citral Catalyzed with Palladium Nanoparticles in $\mathrm{CO}_{2}$-in-Water Emulsion. Green Chem. 2009, 11, 979-985. https://doi.org/10.1039/b821601k.

(23) Vyšniauskas, A.; Kuimova, M. K. A Twisted Tale: Measuring Viscosity and Temperature of Microenvironments Using Molecular Rotors. Int. Rev. Phys. Chem. 2018, 37, 259-285. https://doi.org/10.1080/0144235X.2018.1510461.

(24) Kuimova, M. K. Mapping Viscosity in Cells Using Molecular Rotors. Phys. Chem. Chem. Phys. 2012, 14, 12671-12686. https://doi.org/10.1039/c2cp41674c.

(25) Shimolina, L. E.; Izquierdo, M. A.; López-Duarte, I.; Bull, J. A.; Shirmanova, M. V.; Klapshina, L. G.; Zagaynova, E. V.; Kuimova, M. K. Imaging Tumor Microscopic Viscosity in Vivo Using Molecular Rotors. Sci. Rep. 2017, 7, 1-11. https://doi.org/10.1038/srep41097.

(26) Garg, G.; Foltran, S.; Favier, I.; Pla, D.; Medina-González, Y.; Gómez, M. Palladium Nanoparticles Stabilized by Novel Choline-Based Ionic Liquids in Glycerol Applied in Hydrogenation Reactions. Catal. Today 2020, 346, 69-75. 
https://doi.org/10.1016/j.cattod.2019.01.052.

(27) Haidekker, M. A.; Nipper, M.; Mustafic, A.; Lichlyter, D.; Dakanali, M.; Theodorakis, E. A. Dyes with Segmental Mobility: Molecular Rotors BT - Advanced Fluorescence Reporters in Chemistry and Biology I: Fundamentals and Molecular Design; Demchenko, A. P., Ed.; Springer Berlin Heidelberg: Berlin, Heidelberg, 2010. https://doi.org/10.1007/978-3-64204702-2_8.

(28) Haidekker, M. A.; Theodorakis, E. A. Molecular Rotors-Fluorescent Biosensors for Viscosity and Flow. Org. Biomol. Chem. 2007, 5, 1669-1678. https://doi.org/10.1039/B618415D.

(29) Camy, S.; Condoret, J. S. Modelling and Experimental Study of Separators for Co-Solvent Recovery in a Supercritical Extraction Process. J. Supercrit. Fluids 2006, 38, 51-61. https://doi.org/10.1016/j.supflu.2005.03.005.

(30) Favier, I.; Pla, D.; Gómez, M. Palladium Nanoparticles in Polyols: Synthesis, Catalytic Couplings, and Hydrogenations. Chem. Rev. 2020, 120, 1146-1183. https://doi.org/10.1021/acs.chemrev.9b00204.

(31) Dang-Bao, T.; Pradel, C.; Favier, I.; Gómez, M. Bimetallic Nanocatalysts in Glycerol for Applications in Controlled Synthesis. A Structure-Reactivity Relationship Study. ACS Appl. Nano Mater. 2019, 2, 1033-1044. https://doi.org/10.1021/acsanm.8b02316.

(32) Reina, A.; Pradel, C.; Martin, E.; Teuma, E.; Gómez, M. Palladium Nanoparticles Stabilised by Cinchona-Based Alkaloids in Glycerol: Efficient Catalysts for Surface Assisted Processes. $R S C A d v$. 2016, 6. https://doi.org/10.1039/c6ra19230k. 
(33) Chahdoura, F.; Favier, I.; Gómez, M. Glycerol as Suitable Solvent for the Synthesis of Metallic Species and Catalysis. Chem. - A Eur. J. 2014, 20, 10884-10893. https://doi.org/10.1002/chem.201403534.

(34) Chahdoura, F.; Pradel, C.; Gõmez, M. Palladium Nanoparticles in Glycerol: A Versatile Catalytic System for C-X Bond Formation and Hydrogenation Processes. Adv. Synth.Catal. 2013, 355, 3648-3660. https://doi.org/10.1002/adsc.201300753.

(35) Atilhan, M.; Aparicio, S. Molecular Dynamics Simulations of Metal Nanoparticles in Deep Eutectic Solvents. J. Phys. Chem. C 2018, 122, 18029-18039. https://doi.org/10.1021/acs.jpcc.8b02582.

(36) Medina-Gonzalez, Y.; Tassaing, T.; Camy, S.; Condoret, J.-S. Phase Equilibrium of the CO2/Glycerol System: Experimental Data by in Situ FT-IR Spectroscopy and Thermodynamic Modeling. J. Supercrit. Fluids 2013, 73, 97-107. https://doi.org/10.1016/j.supflu.2012.11.012.

(37) Percevault, L.; Jani, A.; Sohier, T.; Noirez, L.; Paquin, L.; Gauffre, F.; Morineau, D. Do Deep Eutectic Solvents Form Uniform Mixtures Beyond Molecular Microheterogeneities? J. Phys. Chem. B 2020, 124, 9126-9135. https://doi.org/10.1021/acs.jpcb.0c06317.

(38) Herrera, C.; de Carvalho Costa, G.; Atilhan, M.; Costa, L. T.; Aparicio, S. A Theoretical Study on Aminoacid-Based Ionic Liquids with Acid Gases and Water. J. Mol. Liq. 2017, 225, 347-356. https://doi.org/10.1016/j.molliq.2016.11.086.

(39) Liu, L.; Corma, A. Metal Catalysts for Heterogeneous Catalysis: From Single Atoms to Nanoclusters and Nanoparticles. Chem. Rev. 2018, 118, 4981-5079. 
https://doi.org/10.1021/acs.chemrev.7b00776.

(40) Jiang, F.; Cai, J.; Liu, B.; Xu, Y.; Liu, X. Particle Size Effects in the Selective Hydrogenation of Cinnamaldehyde over Supported Palladium Catalysts. $R S C A d v$. 2016, 6 , 75541-75551. https://doi.org/10.1039/c6ra17000e.

(41) Simon, N. M.; Abarca, G.; Scholten, J. D.; Domingos, J. B.; Mecerreyes, D.; Dupont, J. Structural, Electronic and Catalytic Properties of Palladium Nanoparticles Supported on Poly(Ionic Liquid). Appl. Catal. A Gen. 2018, 562, 79-86. https://doi.org/10.1016/j.apcata.2018.06.001.

(42) Wilson, O. M.; Knecht, M. R.; Garcia-Martinez, J. C.; Crooks, R. M. Effect of Pd Nanoparticle Size on the Catalytic Hydrogenation of Allyl Alcohol. J.Am. Chem. Soc. 2006, 128, 4510-4511. https://doi.org/10.1021/ja058217m.

(43) Kuai, L.; Chen, Z.; Liu, S.; Kan, E.; Yu, N.; Ren, Y.; Fang, C.; Li, X.; Li, Y.; Geng, B. Titania Supported Synergistic Palladium Single Atoms and Nanoparticles for Room Temperature Ketone and Aldehydes Hydrogenation. Nat. Commun. 2020, 11, 1-9. https://doi.org/10.1038/s41467-019-13941-5.

(44) Erkey, C.; Madras, G.; Orejuela, M.; Akgerman, A. Supercritical Carbon Dioxide Extraction of Organics from Soil. Environ. Sci. Technol. 1993, 27, 1225-1231. https://doi.org/10.1021/es00043a025.

(45) Serbanovic, A.; Branco, L. C.; Nunes Da Ponte, M.; Afonso, C. A. M. Osmium Catalyzed Asymmetric Dihydroxylation of Methyl Trans-Cinnamate in Ionic Liquids, Followed by Supercritical $\mathrm{CO}_{2}$ Product Recovery. J. Organomet. Chem. 2005, 690, 3600-3608. 
https://doi.org/10.1016/j.jorganchem.2005.04.025.

(46) Chang, L.-H.; Jong, T.-T.; Huang, H.-S.; Nien, Y.-F.; Chang, C.-M. J. Supercritical Carbon Dioxide Extraction of Turmeric Oil from Curcuma Longa Linn and Purification of $\begin{array}{lllll}\text { Turmerones. } & \text { Sep. } & \text { Purif. } & \text { Technol. }\end{array}$ https://doi.org/10.1016/j.seppur.2005.06.018.

(47) Rovetto, L. J.; Aieta, N. V. Supercritical Carbon Dioxide Extraction of Cannabinoids from Cannabis Sativa L. J. Supercrit. Fluids 2017, 129, 16-27. https://doi.org/10.1016/j.supflu.2017.03.014.

(48) Gu, Y.; Jérôme, F. Glycerol as a Sustainable Solvent for Green Chemistry. Green Chem. 2010, 12, 1127-1138. https://doi.org/10.1039/C001628D

(49) Chen, C.-Y.; Chang, J.-K.; Tsai, W.-T.; Hung, C.-H. Uniform Dispersion of Pd Nanoparticles on Carbon Nanostructures Using a Supercritical Fluid Deposition Technique and Their Catalytic Performance towards Hydrogen Spillover. J. Mater. Chem. 2011, 21, 19063-19068. https://doi.org/10.1039/C1JM13528G.

(50) Yoshida, H.; Zama, T.; Fujita, S.; Panpranot, J.; Arai, M. Liquid Phase Hydrogenation of Phenylacetylene over Pd and PdZn Catalysts in Toluene: Effects of Alloying and $\mathrm{CO}_{2}$ Pressurization. RSC Adv. 2014, 4, 24922-24928. https://doi.org/10.1039/C4RA02220C.

(51) Nanao, H.; Murakami, Y.; Sato, O.; Yamaguchi, A.; Hiyoshi, N.; Shirai, M. Furfuryl Alcohol and Furfural Hydrogenation over Activated Carbon-Supported Palladium Catalyst in Presence of Water and Carbon Dioxide. ChemistrySelect 2017, 2, 2471-2475. https://doi.org/10.1002/slct.201700382. 
(52) Kriaa, K.; Serin, J.-P.; Contamine, F.; Cézac, P.; Mercadier, J. 2-Butyne-1,4-Diol Hydrogenation in Supercritical $\mathrm{CO}_{2}$ : Effect of Hydrogen Concentration. J. Supercrit. Fluids 2009, 49, 227-232. https://doi.org/10.1016/j.supflu.2009.01.004.

(53) Arunajatesan, V.; Subramaniam, B.; Hutchenson, K. W.; Herkes, F. E. Fixed-Bed Hydrogenation of Organic Compounds in Supercritical Carbon Dioxide. Chem. Eng. Sci. 2001, 56, 1363-1369. https://doi.org/10.1016/S0009-2509(00)00359-6.

(54) Burgener, M.; Ferri, D.; Grunwaldt, J.-D.; Mallat, T.; Baiker, A. Supercritical Carbon Dioxide: An Inert Solvent for Catalytic Hydrogenation? J. Phys. Chem. B 2005, 109, 16794-16800. https://doi.org/10.1021/jp0521353.

(55) Kassem, S.; van Leeuwen, T.; Lubbe, A. S.; Wilson, M. R.; Feringa, B. L.; Leigh, D. A. Artificial Molecular Motors. Chem. Soc. Rev. 2017, 46, 2592-2621. https://doi.org/10.1039/C7CS00245A.

(56) Lee, S.-C.; Heo, J.; Woo, H. C.; Lee, J.-A.; Seo, Y. H.; Lee, C.-L.; Kim, S.; Kwon, O.-P. Fluorescent Molecular Rotors for Viscosity Sensors. Chem. - A Eur. J. 2018, 24, 1370613718. https://doi.org/10.1002/chem.201801389.

(57) Koumura, N.; Zijlstra, R. W. J.; van Delden, R. A.; Harada, N.; Feringa, B. L. Light-Driven Monodirectional Molecular Rotor. Nature 1999, 401, 152-155. https://doi.org/10.1038/43646.

(58) Kung, C. E.; Reed, J. K. Microviscosity Measurements of Phospholipid Bilayers Using Fluorescent Dyes That Undergo Torsional Relaxation. Biochemistry 1986, 25, 6114-6121. https://doi.org/10.1021/bi00368a042. 
(59) Kung, C. E.; Reed, J. K. Fluorescent Molecular Rotors: A New Class of Probes for Tubulin Structure and Assembly. Biochemistry 1989, 28, 6678-6686. https://doi.org/10.1021/bi00442a022.

(60) Sasaki, S.; Drummen, G. P. C.; Konishi, G. I. Recent Advances in Twisted Intramolecular Charge Transfer (TICT) Fluorescence and Related Phenomena in Materials Chemistry. $J$. Mater. Chem. C 2016, 4 (14), 2731-2743. https://doi.org/10.1039/c5tc03933a.

(61) Mustafic, A.; Elbel, K. M.; Theodorakis, E. A.; Haidekker, M. Apparent Shear Sensitivity of Molecular Rotors in Various Solvents. J. Fluoresc. 2015, 25, 729-738. https://doi.org/10.1007/s10895-015-1559-4.

(62) Haidekker, M. A.; Akers, W.; Lichlyter, D.; Brady, T. P.; Theodorakis, E. A. Sensing of Flow and Shear Stress Using Fluorescent Molecular Rotors. Sens. Lett. 2005, 3, 42-48. https://doi.org/10.1166/s1.2005.003.

(63) Li, H.; Maroncelli, M. Solvation and Solvatochromism in $\mathrm{CO}_{2}$-Expanded Liquids. 1. Simulations of the Solvent Systems $\mathrm{CO}_{2}+$ Cyclohexane, Acetonitrile, and Methanol. $J$. Phys. Chem. B 2006, 110, 21189-21197. https://doi.org/10.1021/jp064166j.

(64) Jin, H.; O’Hare, B.; Dong, J.; Arzhantsev, S.; Baker, G. A.; Wishart, J. F.; Benesi, A. J.; Maroncelli, M. Physical Properties of Ionic Liquids Consisting of the 1-Butyl-3Methylimidazolium Cation with Various Anions and the Bis(Trifluoromethylsulfonyl)Imide Anion with Various Cations. J. Phys. Chem. B 2008, 112, 81-92. https://doi.org/10.1021/jp076462h.

(65) Granero-Fernandez, E.; Machin, D.; Lacaze-Dufaure, C.; Camy, S.; Condoret, J.-S.; 
Gerbaud, V.; Charpentier, P. A.; Medina-Gonzalez, Y. $\mathrm{CO}_{2}$-Expanded Alkyl Acetates: Physicochemical and Molecular Modeling Study and Applications in Chemical Processes. ACS Sustain. Chem. Eng. 2018, 6, 7627-7637. https://doi.org/10.1021/acssuschemeng.8b00454.

(66) Crespo, E. A.; Costa, J. M. L.; Palma, A. M.; Soares, B.; Carmen Martín, M.; Segovia, J. J.; Carvalho, P. J.; Coutinho, J. A. P. Thermodynamic Characterization of Deep Eutectic Solvents at High Pressures. Fluid Phase Equilib. 2019, 500, 112249. https://doi.org/10.1016/j.fluid.2019.112249.

(67) Bloomfield, V. A.; Dewan, R. K. Viscosity of Liquid Mixtures. J. Phys. Chem. 1971, 75, 3113-3119. https://doi.org/10.1021/j100689a014.

(68) Mahajan, A. R.; Mirgane, S. R. Excess Molar Volumes and Viscosities for the Binary Mixtures of N-Octane, n-Decane, n-Dodecane, and n-Tetradecane with Octan-2-Ol at 298.15 K. J. Thermodyn. 2013, pp 1-12. https://doi.org/10.1155/2013/571918.

(69) Lemmon, E. W.; McLinden, M. O.; Friend, D. G. NIST Chemistry WebBook, NIST Standard Reference Database; Linstrom, P. J., Mallard, W. G., Eds.; 2017. https://doi.org/10.18434/T4D303.

(70) Kumar, A.; Singh, T.; Gardas, R. L.; Coutinho, J. A. P. Non-Ideal Behaviour of a Room Temperature Ionic Liquid in an Alkoxyethanol or Poly Ethers at $\mathrm{T}=(298.15$ to 318.15$) \mathrm{K}$. J. Chem. Thermodyn. 2008, 40, 32-39. https://doi.org/10.1016/j.jct.2007.06.002.

(71) Sih, R.; Dehghani, F.; Foster, N. R. Viscosity Measurements on Gas Expanded Liquid Systems-Methanol and Carbon Dioxide. J. Supercrit. Fluids 2007, 41, 148-157. 
https://doi.org/10.1016/j.supflu.2006.09.002.

(72) Luo, X. Y.; Fan, X.; Shi, G. L.; Li, H. R.; Wang, C. M. Decreasing the Viscosity in $\mathrm{CO}_{2}$ Capture by Amino-Functionalized Ionic Liquids through the Formation of Intramolecular Hydrogen Bond. J. Phys. Chem. B 2016, 120, 2807-2813. https://doi.org/10.1021/acs.jpcb.5b10553.

(73) Blanchard, L. A.; Brennecke, J. F. Recovery of Organic Products from Ionic Liquids Using Supercritical Carbon Dioxide. Ind. Eng. Chem. Res. 2001, 40, 287-292. https://doi.org/10.1021/ie000710d.

(74) Kaintz, A.; Baker, G.; Benesi, A.; Maroncelli, M. Solute Diffusion in Ionic Liquids, NMR Measurements and Comparisons to Conventional Solvents. J. Phys. Chem. B 2013, 117, 11697-11708. https://doi.org/10.1021/jp405393d.

(75) Zhao, Y. H.; Abraham, M. H.; Zissimos, A. M. Fast Calculation of van Der Waals Volume as a Sum of Atomic and Bond. J. Org. Chem. 2003, 68, 7368-7373. https://doi.org/10.1021/jo034808o. 